\title{
An Engagement Model for Learning: Providing a Framework to Identify Technology Services
}

\author{
I.T. Hawryszkiewycz \\ Department of Information Systems, \\ University of Technology, Sydney, Australia \\ igorh@it.uts.edu.au \\ Abstract
}

The paper introduces the concept of engagement as a way of modeling and implementing flexible learning processes. The paper particularly addresses new learning demands, such as personalized learning, and defines ways of defining learning processes to support such new demands. It then shows how engagements can be used to provide guidelines for selecting information technology services that meet such new demands.

Keywords: Learning Process, Collaboration, Learning Object

\section{Introduction}

There is increasing demand for education providers to meet new learning demands such as personalized and learner driven education, or developing competencies (Hezemans \& Ritzen, 2002) using constructivist learning methods. One question that arises here is whether a general approach can be found where such different requirements can be met using a generalized approach. Such an approach requires different environments to be constructed from similar learning objects (de Salas \& Ellis, 2006; Koper 2000). The paper proposes that such a generalized approach be based on modeling learning processes and proposes viewing such learning processes in terms of the generic concept of engagements. The paper uses the term engagement because of its natural emphasis of people working, or engaged, with each other in some common goal and learning from each other during the engagement. Thus typical engagements can be to propose a solution, or explain some new material. The goal of this paper is to provide a generic definition of engagements and show how they can be combined into learning processes.

The paper first defines a terminology before outlining how learning processes can be described in terms of engagements. The emphasis in this paper is on process, which is central to this paper. Similar to business processes, a learning process can be seen as a set of activities that are followed in some sequence to achieve a learning goal. There are alternatives for describing learning processes, ranging from pedagogical issues to the practical issues of supporting learning using information technology. From a pedagogical perspective, a learning process taking the form of a

Material published as part of this publication, either on-line or in print, is copyrighted by the Informing Science Institute. Permission to make digital or paper copy of part or all of these works for personal or classroom use is granted without fee provided that the copies are not made or distributed for profit or commercial advantage AND that copies 1) bear this notice in full and 2) give the full citation on the first page. It is permissible to abstract these works so long as credit is given. To copy in all other cases or to republish or to post on a server or to redistribute to lists requires specific permission and payment of a fee. Contact Publisher@InformingScience.org to request redistribution permission. number of cognitive activities (which when combined), satisfies the learning goal. Learners construct their knowledge during the activity. Most activities in the learning process are composed of engagements, where a number of people share and exchange knowledge. Engagements are then combined to form a larger learning process. From an information technology perspective, learning process is often seen as the steps that are 
followed in learning, and ways that people use technology to carry out these steps. The learning process must identify the technology to support the learning activity. Engagements are part of the learning process and provide a basis for defining the information technology services needed at each learning step.

\section{A View of Engagements}

Figure 1 shows some of the kinds of engagements found in learning environment, together with the roles that participate in such engagements. These include:

- Students engaging with content, which may be simply reading material or it may be studying using a simulation program,

- Students engaging with each other while working in groups on a common project where students distribute responsibilities but must coordinate their activities.

- Teachers engaging with students to provide guidance or to assess progress.

- Students engaging with administration to setup and manage a study program.

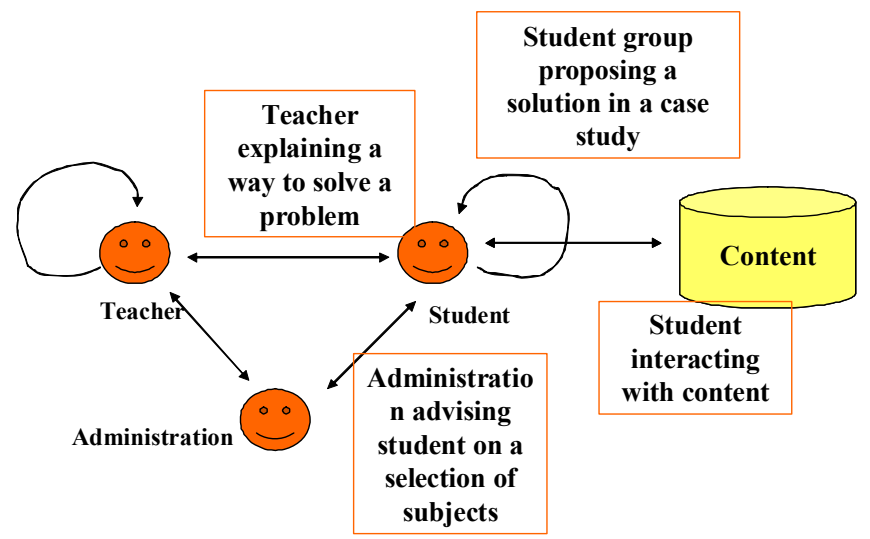

Figure 1: The variety of engagements in teaching and learning

A learning process is made up of a combination of such engagements.

\section{Some Aspects of the Process Definition}

The type of engagement depends on the two major alternatives - instructivist and constructivist approaches. The principal difference is that in the instructivist approach, the learner is instructed how to proceed. In the constructivist approach learners select their own learning sequence. Thus in the instructivist approach students build up their knowledge by following predefined steps, with prespecified requirements for each step. Here usually skills are developed out of context (learning data modeling through the study of theoretical structures and languages with minimal reference to their application). The engagements in this case are highly structured and the context specially designed to concentrate on a technique that is being taught.

In the constructivist approach students build their knowledge through experiences in context usually a case study. Recent educational approaches are also placing more emphasis on constructivist learning approaches (Jonassen, 1999), where learners construct knowledge in their preferred ways. A learner sets or is set a learning goal and develops a learning plan and is provided with learning materials. In educational institutions, the learning plan is usually a set of lectures and assessments that is followed by all the students taking a subject. In industry the context is the current business activity. 
We address ways to customize such plans to specialized learner needs for large numbers of learners by suggesting the best engagements for them to participate in. The learners are then guided through their specialized plan using support systems to minimize the effort needed to manage the plans by teachers. Such guidance can take many forms. It may be to identify a lack of some elementary knowledge and provide ways to build familiarity of this knowledge before continuing with the main learning plan. One further advantage in formulating plans is support constructivist learning, which some writers (Petraglia, 1998) suggest are not effectively supported in current systems. In this case, learners usually choose their engagements and often require support to customize them to their needs.

\section{A Conceptual Framework for Describing Learning}

Figure 2 illustrates the main concepts in the approach described here. These are similar to other existing approaches such as that of Wang (2005). The main elements are:

- Learning environment, or where learning takes place. This may be a University of a person's place of work.

- Learning goal, which describes the learning objective,

- Learning plan, which defines the sequence of learning activities to be followed to achieve the learning goal. The sequence of activities is here called a learning process. The process is made up of a set of activities arranged into a sequence of steps.

- Learning activity, which describes a step of the learning plan and uses a selected learning method,

- Subject metadata, which provides explicit references to information needed in the activity,

- The learning method, which is used during the activity, and which can include a number of engagements,

- Support services provided for the engagements in the learning method.

The approach proposed here is to first define the learning goal and then propose a plan to achieve this goal. The plan is composed of a number of learning activities, which are followed in a sequence here called the learning process. The learning activities are realized through engagements. The engagements are then constructed out of one or more learning objects in a way similar to that in Koper (2000). Figure 2 provides our framework for placing the learning activities within a practical context. Thus for example, support services depend on the environment in which learning takes place. The learning proceeds in accordance with a plan. How the plan is set depends on the environment and its policies and services. Similarly the method used to support learning activities depends on available support services and learning process.

\section{Engagements - What are they?}

An engagement is a number of interactions to achieve a learning sub-goal within a larger goal such as that described in Bednar, Eglin, and Welch (2007). For example, preparing and assessing an assignment may include a number of engagements, such as clarifying the problem, discussion with peers, or looking up references. This is followed by the actual writing of the assignment and by its assessment. Each of these engagements includes a number of roles. It is necessary to identify the roles in the engagement and the interactions between them. The interactions go beyond simple exchanges of individual messages, but involve sequences of messages towards some goal. We use the term engagement as a concept to group such messages into sequences that achieve some goal. We then define the communications needed between the different roles, and then go into detailed design by identifying engagements followed by providing services to support these engagements. 


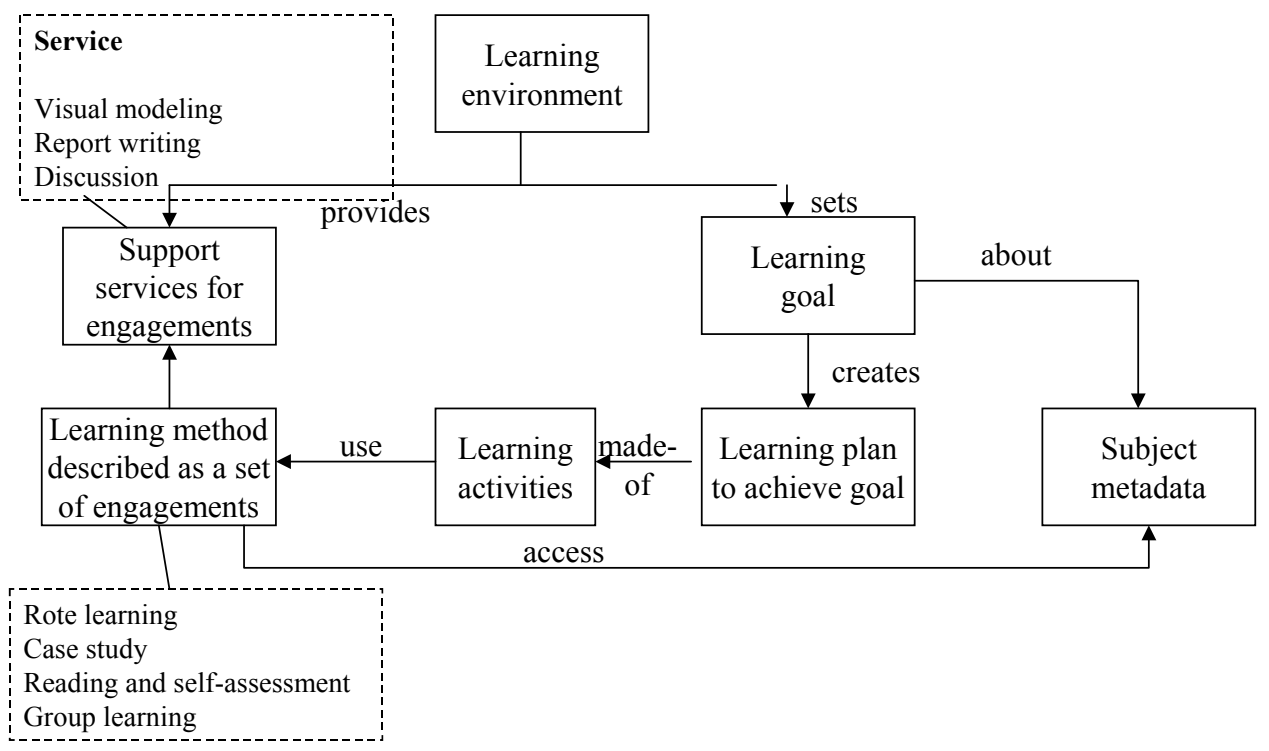

Figure 2: Conceptual model for integrating learning and learning activity processes.

Typical engagements in learning include:

- Preparing a document that may be an assignment or some other report - here called managing an e-portfolio,

- Obtaining feedback following up an assessment,

- Presenting and following up a query,

- Round table discussions on a topic of interest.

\section{Defining Engagements in Detail}

Our goal now is to define engagements in more detail. In theory an engagement can be seen as a composite object shown in Figure 3. There are a number of roles carrying out a number of actions in the engagement. Services such as discussion boards (Harman \& Koohang, 2005) are provided to support the actions. Such services include access to databases required by the actions.

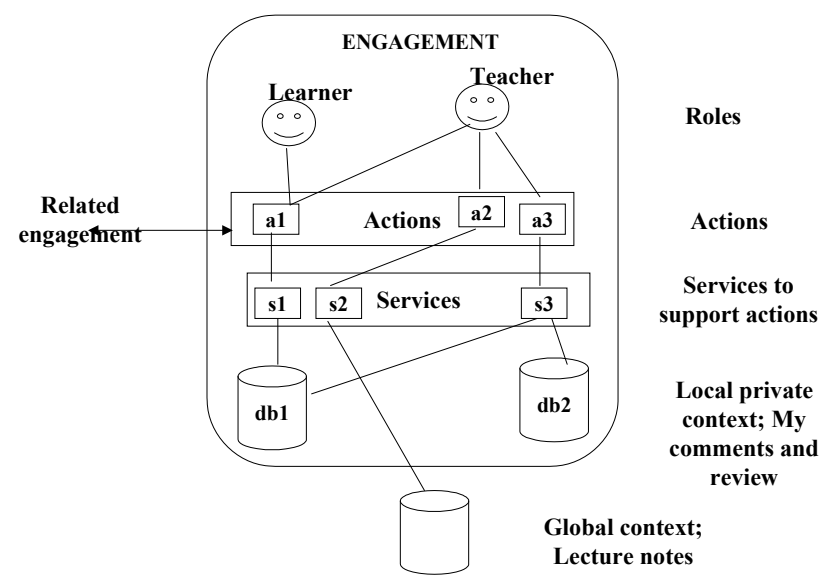

Figure 3: A conceptual model of an engagement 
In summary:

- An engagement has a goal, such as analyze a problem, check a solution, and so on.

- Actions define what must be done to accomplish the goal. These include actions such as update document, discuss with expert

- Services are provided to allow users to carry out the actions. These may be chatrooms, discussion databases.

- Local private context is what is directly needed to complete the engagement, as for example a critique,

- Global context is the knowledge that may be used as background but is not changed, as for example lecture notes.

There are also constraints and permissions, as for example, role permissions for a function. The kinds of actions include:

- Setup a new engagement,

- Invite people to take up a role in the engagement.

- Alert people of actions taken by others in the engagement,

- Update local information,

- Get background information,

- Setup services to support actions in the engagement.

As an example Figure 4 is an example of a simple engagement often found in instructivist learning. Here a teacher assesses a student assignment. The functions are to make the assessment and to explain it to the student. Included often are discussions with the student's peers and problem clarification. The services are an e-meeting to clarify the assessment and a discussion system for gathering comments. The context can include background material as well as general assessment rules.

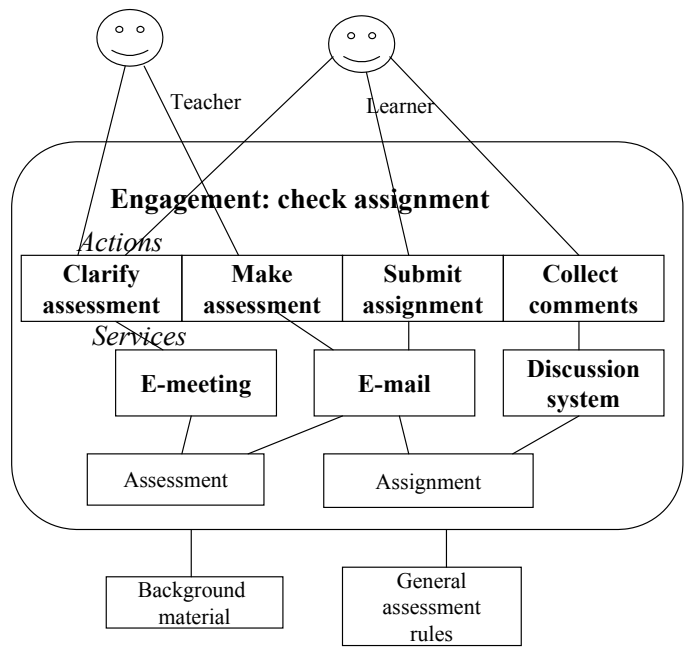

Figure 4: An example of an engagement

The engagement in this case is collaboration in the small being carried out within a larger framework, which is completion of the subject by the student. The issues then are how to subdivide a process into engagements while maintaining links to the entire context. 


\section{Important Considerations in Designing Engagements}

To serve their purpose engagements must satisfy a number of criteria. These include:

- The responsibilities of the engagement roles are clearly defined,

- The services that must be provided in the engagement to adequately support the roles, and

- Provide easy access to the local context,

- Make sure that adequate services are provided for knowledge transfer,

- Making sure that the engagements are consistent with the process.

\section{Modeling Learning Processes in Terms of Engagements}

In their most elementary form, engagements can be seen as supporting the activities in the learning process. As an example Figures 5 and 6 illustrate the kinds of engagements in instructivist and constructivist learning processes. Here each black dot is an activity. The arrows between the dots indicate the sequence of activities in the learning process. The box under the dot lists the engagements in the activity. The difference is that the activities in an instructivist are predefined, often in what is to be achieved and how it is to be achieved. Thus as shown in Figure 5 there is a process step, called 'obtain information' which is made up of two engagements, 'distribute material' and 'explain material'. The explanation in most cases is through a formal lecture, which is modeled as an engagement. In another activity 'tutorial work' a tutor can demonstrate the application of techniques introduced in 'obtain information'. A sample solution is then usually provided and explained, which can be another engagement. Often such engagements involve small groups with interactions between the teacher and learner. The conditions for knowledge transfer are usually satisfied, as there is both the socialization to share tacit knowledge as well as interpret it in terms of the current problem and to evaluate any outcomes.

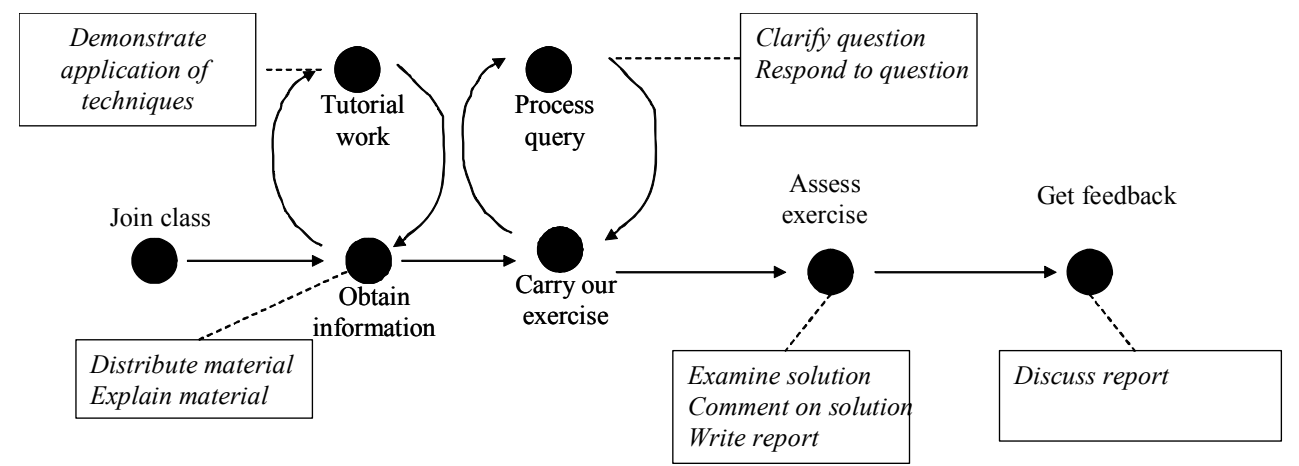

Figure 5: An instructivist learning process expressed in terms of engagements

In the constructivist process, the difference is in choosing the activities to be carried out. Thus, for example, the student is provided with learning objectives and a case study and will have to develop their own study plan to complete the study. The principles are learned in context and hence at times some instructivist learning may have to take place. 


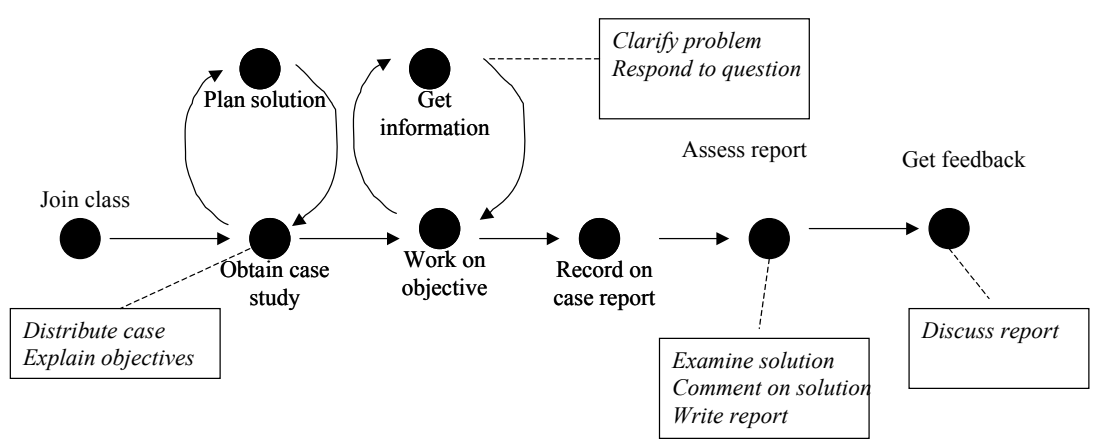

Figure 6: A constructivist learning process expressed as engagements

The engagements are now different as they provide more choice. Thus to facilitate learning in context there is emphasis on setting objectives The engagement now usually involves early analysis, usually in a small group, and learners themselves setting the objective. The teacher often acts as guide in this process. Then in problem solving learners often identify their knowledge gaps and may need to learn new principles or develop new competencies in the context of their case study.

\section{Supporting Engagements}

Our goal is to present all the engagement through a workspace. The current implementation is shown in Figure 7 based on our LiveNet system http://livenet4.it.uts.edu.au (Pan \& Hawryszkiewycz, 2006). The system allows workspaces to be easily constructed by bringing artifacts, learners and services together in the one space. This space includes roles, assigns people to the roles. It also includes the ability to include selected artifacts and services in each workspace. One choice for designers of learning systems based on workspaces is whether a workspace concen-

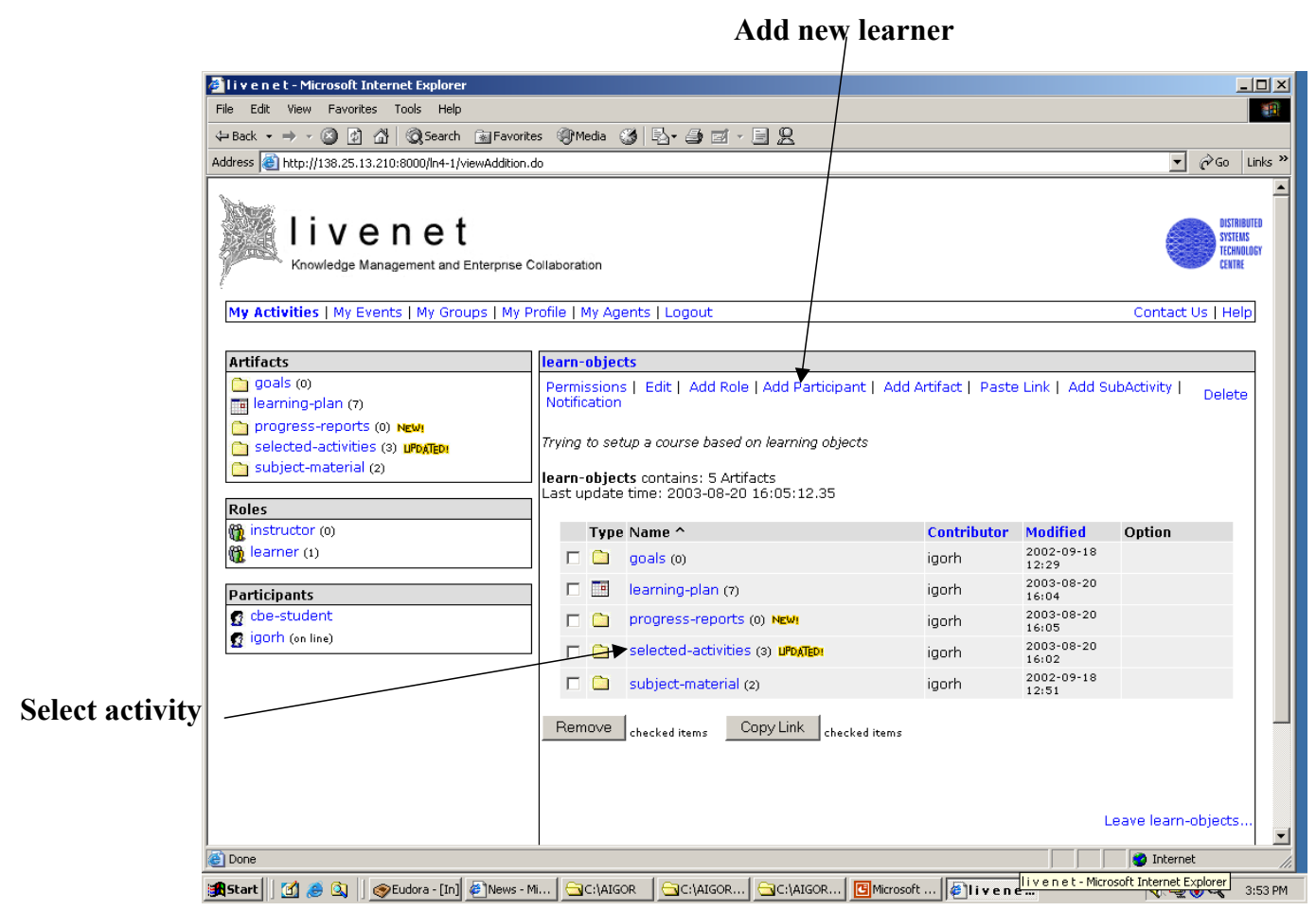

Figure 7: A workspace setup for an engagement 
trates on one engagement or whether it should support a number of engagements. The engagements must also be seen in the context of other activities and the process as a whole to enable learners to move freely between the engagements.

\section{Further Development}

Currently all activities are predefined and there are also predefined methods for each activity. We are currently extending the system to allow greater flexibility. Principally the goal is to support constructivist learning. Two ways are proposed. One is for learners to themselves structure their learning process. The other is to provide useful hints and support for learners to structure and follow their selected learning process. Our other work includes ways to extend support beyond the workspace, principally to mobile devices.

\section{Extending to Constructivist Learning}

Supporting constructivist approaches especially with learner driven systems is not an easy task. They need some support from agents especially in the constructivist approach. Here virtually every student can be carrying out a different study plan, making management an onerous process. A variety of agent support systems have been proposed. One earlier approach was to use pedagogical agents (Baylor \& Kim. 2003) or intelligent tutorial systems. One argument that can be made here is that these primarily support instructivist learning processes. Our approach (Pan \& Hawryszkiewycz, 2006) here is to suggest the use of software agents that support the learning activity process, by suggesting and supporting various engagements. In that context they provide guidance rather than domain expertise. The process agents will know the role responsibilities and bring together the services, context and roles needed to create and support each engagement. The agents are based on the metamodel of collaboration defined in earlier work, which identified the concepts to describe collaborative processes (Hawryszkiewycz, 2005). The collaborative metamodel concepts identify candidates for generic agents (Hawryszkiewycz \& Lin, 2003) and typical multi-agent architectures.

Our use of agents is leading to a more proactive environment, where agents can actually adapt the processes to learner background by both setting up engagements that suit the learner profile and

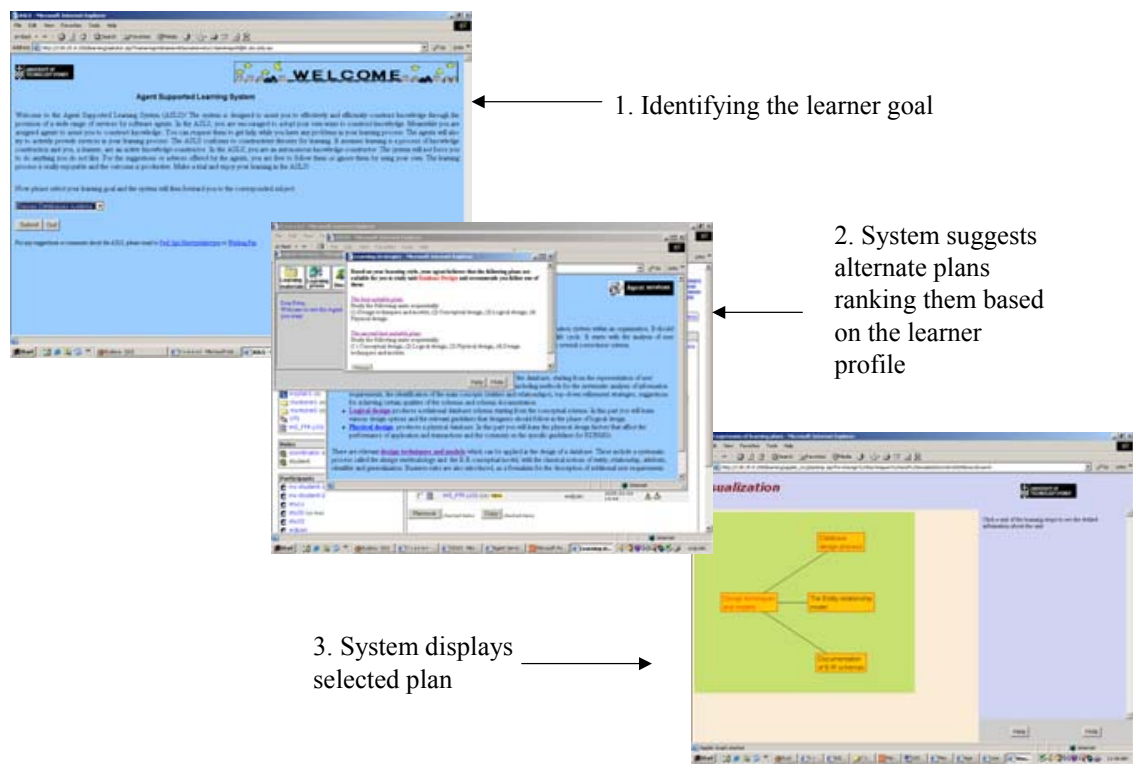

Figure 8: Selecting a learning goal. 
providing hints on how to participate in these engagements. The process here (Pan \& Hawryszkiewycz, 2006) is illustrated briefly in Figure 8. Here a learner selects their learning goal. The system then suggests a learning plan to be followed to achieve the goal and helps the learner proceed through the plan.

\section{Summary}

The paper introduced the idea of engagements and how they can assist learning by providing flexibility to construct personalized learning processes. It proposed a model of engagements and showed how they can be composed to create learning processes. The paper then concentrated on implementation issues. It first illustrated the current state where most engagements are predefined and presented through workspaces. It then suggested that such implementations could be easily extended to support constructivist learning processes through the use of software agents.

\section{References}

Baylor, A., \& Kim, Y. (2003). Validating pedagogical agent roles: Expert, motivator, and mentor. EDMedia 2003, $15^{\text {th }}$. Annual Conference on Educational Multimedia, Hypermedia and Telecommunications, Hawaii, June 2003. 2003.

Bednar, P., Eglin, R., \& Welch, C. (2007). Contextual inquiry: A systematic support for student engagement through reflection. Interdisciplinary Journal of Knowledge and Learning Objects, 3, 45-55. Available at http://ijklo.org/Volume3/IJKLOv3p045-055Bednar341.pdf

DeSalas, L. \& Ellis, L. (2006). The development and implementation of learning objects in a higher education setting. Interdisciplinary Journal of Knowledge and Learning Objects, 2, 1-22. Available at http://ijklo.org/Volume2/v2p001-022deSalas.pdf

Harman, K. \& Koohang, A. (2005). Discussion board: A learning object. Interdisciplinary Journal of Knowledge and Learning Objects, 1, 67-77. Available at http://ijklo.org/Volume1/v1p067077Harman.pdf

Hawryszkiewycz, I.T. (2005). A metamodel for modeling collaborative systems. The Journal of Computer Information Systems, Spring, 63-72.

Hawryszkiewycz, I.T. \& Lin, A. (2003). Process knowledge support for emergent processes. Proceedings of the Second IASTED International Conference on Information and Knowledge Management, Scottsdale, Arizona, November, 2003, pp. 83-87.

Hezemans, M. \& Ritzen, M. (2002). Learning environments: Three types of learning environment. Telelearning: The challenge for the third millennium, IFIP Congress, Montreal, August 2002, Kluwer Academic Publishers, Boston, pp. 185-192.

Jonassen, D. (1999). Constructivist learning environments on the Web: Engaging students in meaningful Learning. EdTech99.

Koper, R. (2000). Modeling units of study from a pedagogical perspective: The pedagogical model behind EML. Retrieved from http://eml.ou.nl/articles

Pan, W. \& Hawryszkiewycz, I.T. (2006). Assisting learners to dynamically adjust learning processes through software agents. International Journal of Intelligent Information Technologies, 2(2), 1-15.

Petraglia, J. (1998). The real world on a short term lease: The (mis)application of constructivism to the design of educational technology. Educational Technology Research and Development, 46(3), 53-65.

Wang, F.H. (2005). Developing web-based virtual classroom based on IMS learning design specification. Proceedings of the Fourth IASTED International Conference on Web-based Education, Grindelwald, pp. 267-272. 


\section{Biography}

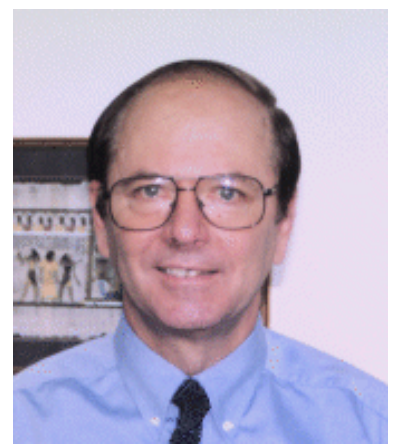

Prof. Hawryszkiewycz completed a BE and ME degrees in Electrical Engineering at the University of Adelaide, and a $\mathrm{PhD}$ degree at the Massachusetts Institute of Technology. His early research covered the design of databases and information systems for business. Since 1987 his work has focused on collaborative work including $g$ the design of collaborative systems with emphasis on knowledge management, including small business networks, or research planning at the World Health Organization (WHO). His team has developed the prototype LiveNet workspace system, that supports collaborative applications. This has included research in the application of collaborative technologies. He has over research 150 publications and 3 text books. 